\section{The renal unit in Inverness: the shape of things to come?}

Some British renal units treat most patients referred with end stage renal failure but still fail to achieve patient treatment rates considered acceptable in other European countries. ${ }^{12}$ Part of the problem is due to inadequate referral of patients by non-specialists. ${ }^{3}$ Because British renal units serve far larger populations than their European counterparts, ${ }^{3}$ it has been suggested that smaller renal units, situated in district general hospitals, might provide a more accessible service and encourage referral. ${ }^{4} \mathrm{We}$ describe the mode of operation and quality of service provided by a small renal unit in a district general hospital, managed by a general physician with an interest in nephrology.

\section{The unit}

The four bedded unit was established in March 1976 and provides dialysis facilities for the Highland Region and Western Isles of Scotland, which has a population of about 231000 (Highland Health Board estimate). Geographically the region is the largest in the United Kingdom. The unit staff consists of two nursing sisters, three staff nurses, one enrolled nurse, a domestic, a part time dialysis technician, and a part time dietitian. To the end of 1983 dialysis facilities were regularly available from 0750 to 1620 on six days a week and the nursing staff introduced an on call rota to deal with out of hours emergencies. Medical cover was provided by a consultant physician with an interest in renal diseases; participation by the junior medical staff has been erratic and unnecessary for the proper working of the service. Vascular access and Tenckhoff catheter insertion were provided by two general surgeons. Criteria for accepting patients on to the programme were not rigorous; most patients referred for treatment were accepted. Most of the patients having dialysis have been placed on the waiting list for a transplant at Aberdeen.

Forty four patients have been treated since March 1976, with an actuarial patient survival of $76 \%$ at one year and $71 \%$ at two years. The patien acceptance rate was 28.1 per million population per year. There were 26 men and 18 women with a mean age of $42 \cdot 4+13.6$ (range 10-62). The ratio of patients aged over 50 to those younger was $0.51(15: 29)$. Three diabetics $(7 \%$ of the dialysis population) were treated.

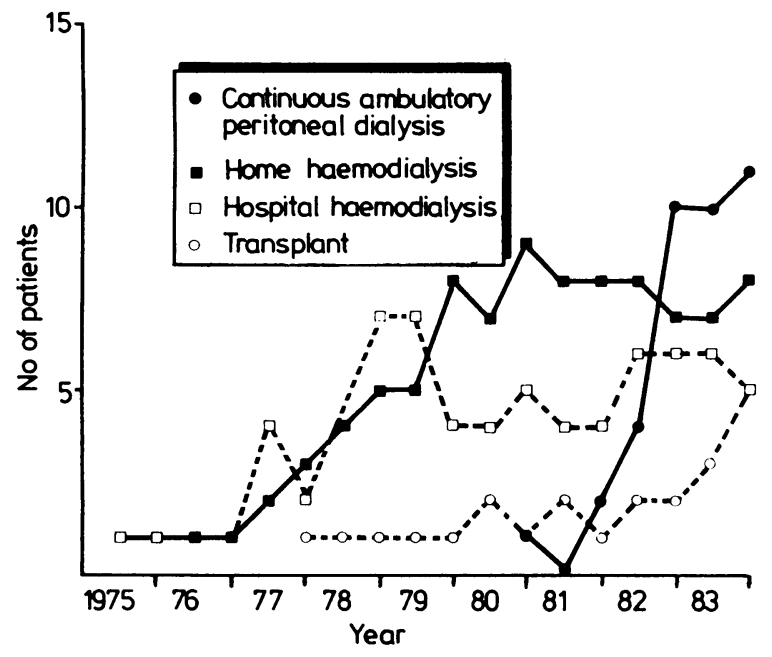

Growth of patient numbers on different forms of treatment, 1975-83.

Continuous ambulatory peritoneal dialysis has been the fastest growing form of treatment in recent years (see figure) and our experience has been very satisfactory. Only two patients have required a change of treatment in 189 patient months; the peritonitis rate has been one episode in seven patien months. Two of the five transplants performed from 1976 to the end of 1983 were from living related donors.

\section{Comment}

We suggest that a single physician with an interest in renal diseases can provide a service in a district general hospital equal to that achieved in larger centres. The main problems with the unit have been those of distance from the local transplant centre and the necessity for continuous medical cover by a single physician.

The advantages of small renal units are obvious. Patients have easier access to a local centre and can establish a close relationship with the nursing staff. Less obviously, such units can offload some of the patient burden from larger centres: we currently treat 29 patients who would otherwise be managed in Aberdeen. Moreover, patient survival rates of $76 \%$ at one year and $71 \%$ at two years are satisfactory when compared with those from the rest of Europe. ${ }^{5}$

Nevertheless, the patient acceptance rate in Inverness (28.1 patients per million per year) is almost identical to that of Scotland as a whole (28.7). ${ }^{3}$ Patient groups which appear to be selected against are those over 50 and diabetics; the ratio of patients over 50 to those under 50 was 0.51 , as against 0.9 and more in comparable European countries, ${ }^{3}$ and only $7 \%$ of the dialysis population were diabetic. The pattern is similar to that noted in the rest of the United Kingdom. ${ }^{3}$ Because few patients have been refused dialysis we assume that many others are never referred. Although the unusual demography of the Highland Region must be remembered, we suggest that the presence of an active local renal unit does not guarantee referral of patients in high risk groups.

We thank the nursing staff, who have enabled this unit to run smoothly, and Mr J Logie, Mr R Baker, and the many surgical senior registrars for their help with surgical problems.

1 Taube DH, Winder EA, Ogg CS, et al. Successful treatment of middle aged and elderly patients with end stage renal disease. Br Med F 1983;286:2018-20.

Nicholls AJ, Waldek S, Platts MM, Moorhead PJ, Brown CB. Impact of coninuous ambulatory peritoneal dialysis

Wing AJ. Why don't the British treat more patients with kidney failure ? Br Med F $1983 ; 287: 1157-8$.

4 Nicholls AJ, Catto GRD, Edward N, Engeset J, Logie JRC, MacLeod M Integrated dialysis and renal transplantation: small is beautiful. Br Med 1980;280:1516-7.

5 Broyer M, Brunner FP, Brynger H, et al. Combined report on regular dialysis and transplantation in Europe. XI, 1980. Proc Eur Dial Transplant Assoc 1981 18:2-58.

(Accepted 8 August 1984)

Division of Medicine, Raigmore Hospital, Inverness IV2 3UJ

J MAIN, MRCP, medical registrar

D A POWER, MRCP, senior medical registrar

J A BURTON, FRCPGLAs, consultant physician

Correspondence to: Dr Burton.

\section{Maggots dyed with chrysoidine: a possible risk to anglers}

Searle and Teale first drew attention in 1982 to the possibility that bladder tumours in coarse fishermen might be the result of exposure to the azo dye chrysoidine. ${ }^{1}$ They initially reported that a study from Poland had shown chrysoidine to be carcinogenic in mice ${ }^{2}$ but later found that this work could not be repeated. An epidemiological study conducted in West Yorkshire failed to find any increased prevalence of use of dyed maggots by patients with bladder cancer, although the authors emphasised that the confidence limits of their study were wide. ${ }^{3}$

It has recently been argued that the evidence for a link between chrysoidine and bladder cancer is now entirely circumstantial, ${ }^{4}$ but until further epidemiological studies and studies of carcinogenicity in animals are conducted I think that any strong circumstantial evidence should be reported.

\section{Case reports}

Two brothers born in 1912 and 1930 had fished together most weekends from 1954 to 1978 often for nine hours a day. They always used dyed maggots for bait, and although they tried several colours they favoured the bronze (chrysoidine stained) variety. Their hands became stained with the dye and it took several days for this to wear off. In winter the maggots became cold and sluggish and the men often put them into their mouths to warm them and "make them more attractive to the fish."

The eldest brother was seen in 1979 with severe haematuria. He subsequently died of uraemia secondary to a transitional cell carcinoma of the bladder proved by histological examination.

The younger brother first noticed haematuria in 1971 at the age of 41 but was not diagnosed as having a bladder tumour until 1976. He later developed an invasive transitional cell carcinoma and underwent radical radiotherapy 